\title{
Effects of Kappa-Carrageenan on the Physico- Chemical Properties of Thermoplastic Starch
}

\author{
Annabelle C. Flores ${ }^{1 *}$, Eric R. Punzalan², and Norberto G. Ambagan ${ }^{1}$ \\ ${ }^{1}$ Department of Science and Technology, Industrial Technology Development Institute, Bicutan, Taguig City \\ ${ }^{2}$ De La Salle University, Manila
}

\begin{abstract}
Food packaging materials derived from renewable sources are highly sought due to their low cost and wide range of functional properties. This research reports on the fabrication and physico-chemical properties of composite films from cassava starch and $x$-carrageenan.
\end{abstract}

Characterization of the films by FTIR indicates physical entanglements between polymer chains. The water solubility of the films showed linear dependency on the $x$-carrageenan content while the moisture content diminished with the addition of $x$-carrageenan. . The mechanical property of the films showed that as the amount of $x$-carrageenan increases, tensile strength exhibited improvement, the water activity $\left(\mathrm{a}_{\mathrm{w}}\right)$ increased, and $\mathrm{pH}$ became more basic, while \% elongation weakened. Water vapour transmission rate (WVTR) improved significantly from $82.73 \mathrm{~g} /\left(\mathrm{m}^{2}\right.$.day) for pure thermoplastic starch to 11.31 $\mathrm{g} /\left(\mathrm{m}^{2}\right.$.day) for $90 / 10 \%(\mathrm{w} / \mathrm{w})$ starch $/ x$-carrageenan ratio, which is comparable to WVTR of commercial polypropylene.

Keywords: thermoplastic starch; film; biofilm; cassava starch; carrageenan

\section{INTRODUCTION}

The increasing demand of consumers for healthier and more natural foods has motivated researchers to develop biodegradable packaging materials that are able to extend shelf life and protect the integrity of food. The usual food packaging materials are made of synthetic polymers due to its high flexibility, durability, and economic viability. However, because of its nonbiodegradable property, it caused severe problems in plastic wastes disposal (Muller, 2005). Hence, new materials based on biodegradable polymers are highly sought. Films and coatings from agro-resources are of great interest because of its biodegradability, edibility, biocompatibility, appearance, and barrier properties (Muller, 2005). These films or coatings can also carry antimicrobial and antioxidant compounds which help reduce the rate of rancidity, load of spoilage and pathogen microorganisms, as well as restricting the volatile flavor lost (Perez-Perez, et al., 2006). Manufacturing of films requires careful attention especially on its mechanical and chemical properties, availability, and cost. 
Importantly, disposal at the end of its useful life must be considered.

Polysaccharides, like starch, are potential packaging material due to its strong mechanical and gas barrier properties (McHugh, et al., 2009). However, films from starches are oftentimes stiff and brittle, hence addition of plasticizers, like low molecular weight poly alcohols (e.g. glycerol, sorbitol), are usually done (Sothornvit and Krochta, 2000) to reduce intermolecular forces increasing the chain mobility of macromolecules resulting to the improvement of the chain's flexibility (McHugh, et al., 2009). The presence of plasticizers, however, increases the film permeability (Sothornvit and Krochta, 2000) affecting its function in protecting the food. Hence this study reports the effect of reinforcing the thermoplastic starch with naturally occurring carrageenan.

\section{EXPERIMENTAL}

Materials, Reagents, and Methods. Cassava starch (Phil-Agro Industrial Corporation), Kappa-carrageenan (Marcel Trading Corporation), and glycerol (AR, Alyson Chemical Industry) were used as received.

IR spectra were measured using ABB FTIR, (MB3000, light source 750 to $4000 \mathrm{~cm}^{-1}$ ). Film color was determined using Minolta Chroma Meter (CT-310), and evaluated using the CIELab method. Film surface morphologies were examined using Scanning Electron Microscope (SEM) (JOEL Ltd., 10 kVgold coated). Moisture content was done using the Vacuum Oven Method following the AOAC Official Method 925.09.

Water solubility tests were measured using the protocol developed by Fazila, et al. (2007). Water activity $\left(a_{\mathrm{w}}\right)$ of the film was measured in triplicate using Novasina water activity meter ( $\mathrm{a}_{\mathrm{w}}$ dish $=2 / 3$ of its volume). $\mathrm{pH}$ was determined (AOAC 1995 official method). The barrier property of the film was determined using MOCON PERMATRANWR 3/33. The mechanical properties (tensile strength and \% elongation), and thickness of the films was measured following the ASTM D 882-02: Standard Test Method for Tensile Properties of Thin Plastic Sheeting.

Film Preparation. The method developed by Bourtoom (2007) was used with modification in the formation of film. Three grams of the solid matter (cassava starch or cassava starch/kappa-carrageenan blends) were dispersed for every $100 \mathrm{~mL}$ of distilled water and a solution of glycerol $(30 \mathrm{~g} / 100 \mathrm{~g}$ of solid matter) were added. The resulting mixtures were gelatinized at $68-70{ }^{\circ} \mathrm{C}$ for $15-20$ minutes with continuous stirring to ensure total solubilization of starch destructing its semicrystalline granules. Cassava starch-kappacarrageenan blends were varied at the ratio of (w/w): 100:0, 90:10, 80:20, 70:30, 60:40, and 50:50. Air bubbles from the film-forming solutions were removed using a vacuum oven. The gelatinized mixture was then poured onto a non-stick tray which has a measurement of $12.6 \times 8.6 \mathrm{in}^{2}$, and kept in a drying oven for 24 hours at a controlled temperature of $50{ }^{\circ} \mathrm{C}$.

\section{RESULTS AND DISCUSSION}

The formation of the starch film or composite film through the dispersion of components in aqueous media is achieved at $70{ }^{\circ} \mathrm{C}$ to produce flexible and transparent films. The pure starch film showed formation of wrinkles when left at room temperature. Wrinkling may be attributed to the hygroscopic nature of the starch, and to the heat and water applied in its preparation. This is because as gelatinization occurs, heat and water weaken the inter- and intra-molecular bonds in the film-forming solution. When the bonds are broken, the structures become less rigid making them move freely. When the film-forming solution dries and cools, the molecular bonds become intertwined with each other giving rise to the wrinkles.

The starch solution with added kappacarrageenan readily dissolved in water and formed smooth films even at room temperature. Kappa-carrageenan contributed to the formation of more rigid network making the film less hygroscopic. 


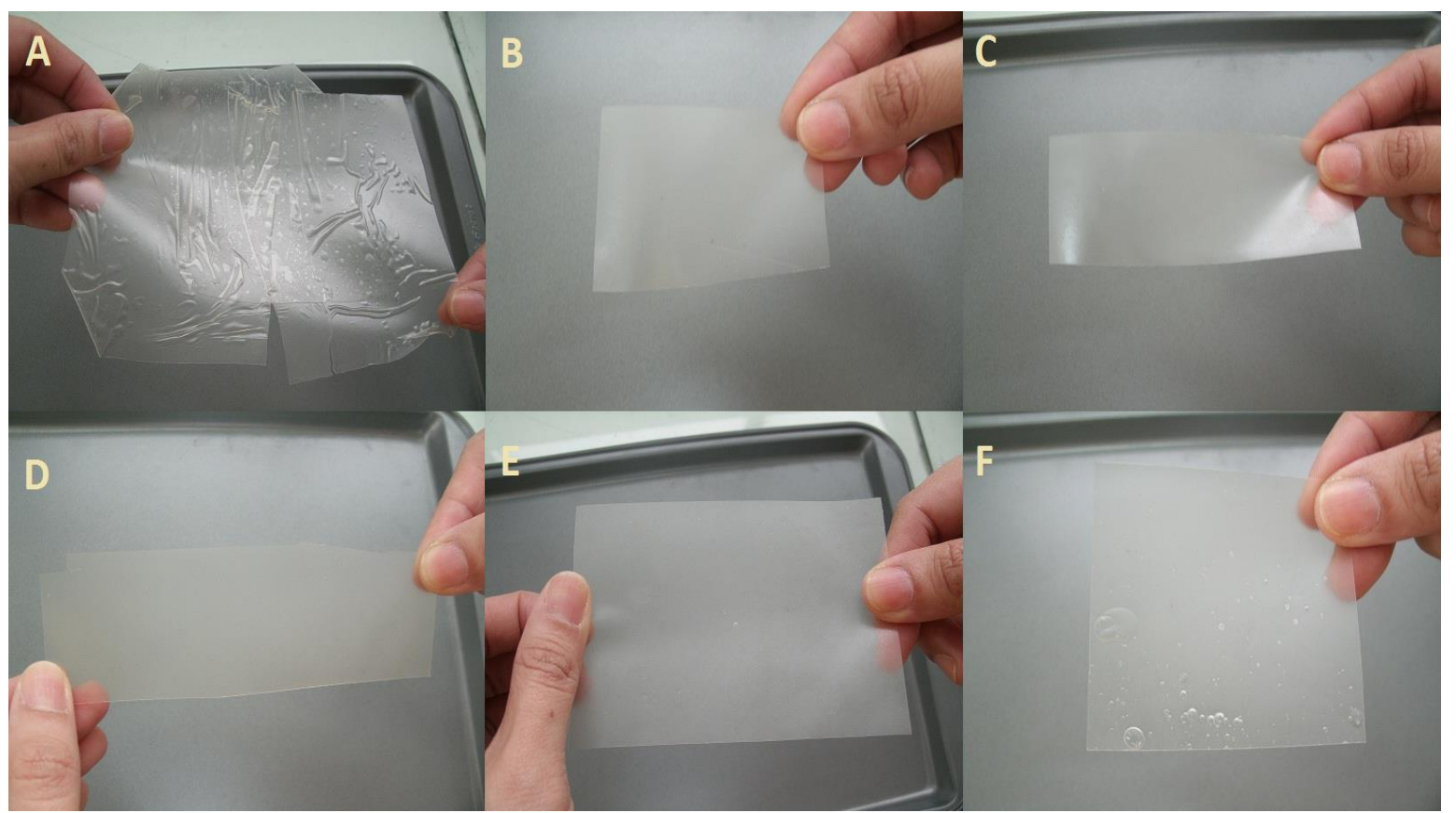

Figure 1. Films with Different Starch/ x-carrageenan blends (w/w): (A) 100/0; (B) 90/10; (C) 80/20; (D) 70/30; (E) 60/40; (F) 50/50.

The viscosity of the solution increases with the amount of kappa-carrageenan with the 50/50 starch $/ \mathrm{k}$-carrageenan blend as the most viscous making it difficult to obtain a homogenous mixture resulting to formation of bubbles upon film drying. Nonetheless, all the films were easily removed from the non-stick tray.

The resulting films (Figure 1) are generally smooth except for the 100\% starch film (Figure 1A) which shows a wrinkled surface. The presence of bubbles can be observed on the film made from 50/50 composite (Figure 1F).

IR analyses showed no significance change in the functional groups. Slight shifting of the absorption peaks, however, can be observed for C-O-C band from $1010.63 \mathrm{~cm}^{-1}(100 / 0)$ to $1002.91 \mathrm{~cm}^{-1}(90 / 10)$, and for C-H band from
$2391.56 \mathrm{~cm}^{-1}(100 / 0)$ to $2399.27 \mathrm{~cm}^{-1}(90 / 10)$ suggesting physical entanglements between cassava starch and kappa-carrageenan possibly due to hydrogen bonding. The same observations were noted by Martins, et al. (2011) for the composite film of kappacarrageenan and locust bean gum.

The color of the resulting films, which is a major factor in commercial acceptability, was determined by the CIELAB method using Minolta Chromameter. Table 1 presents the values of the lightness variable $\left(\mathrm{L}^{*}\right)$, the color coordinate between red and green $\left(\mathrm{a}^{*}\right)$, and the color coordinate between yellow and blue ( $\left.\mathrm{b}^{*}\right)$ of the films. The computed delta values $\Delta \mathrm{L}^{*}, \Delta \mathrm{a}^{*}$, and $\Delta \mathrm{b}^{*}$ indicating how the samples differ from the set reference or standard and the computed color difference $\Delta \mathrm{E}^{*}$ are also presented.

\section{Table 1: Color Parameters of the Films with Different Starch/ $\varkappa$-Carrageenan Ratio.}

\begin{tabular}{cccccccc}
\hline $\begin{array}{c}\text { Starch/ } \\
\text { k-car ratio }\end{array}$ & $\mathbf{L}^{*}$ & $\mathbf{a}^{*}$ & $\mathbf{b}^{*}$ & $\mathbf{\Delta} \mathbf{L}^{*}$ & $\mathbf{\Delta a}^{*}$ & $\mathbf{\Delta} \mathbf{b}^{*}$ & $\mathbf{\Delta E}^{*}$ \\
\hline $100 / 0$ & 61.20 & +0.21 & +1.11 & reference & reference & reference & reference \\
\hline $90 / 10$ & 61.80 & +0.19 & +0.60 & 0.60 & -0.02 & -0.51 & 1.03 \\
\hline $80 / 20$ & 60.00 & +0.14 & +0.91 & -1.20 & -0.07 & -0.20 & 1.01 \\
\hline $70 / 30$ & 60.98 & +0.12 & +1.11 & -0.22 & -0.09 & 0.00 & 0.14 \\
\hline $6 / 40$ & 60.83 & -0.18 & +0.76 & -0.37 & -0.39 & -0.35 & 0.47 \\
\hline $50 / 50$ & 60.32 & -0.33 & +0.54 & -0.88 & -0.54 & -0.57 & 0.96 \\
\hline
\end{tabular}


Setting 100/0 starch/ $x$-carrageenan blend as the reference, it can be deduced from Table 1 that the film with $90 / 10 \%$ starch/kappacarrageenan ratio was lighter $\left(\Delta \mathrm{L}^{*}\right)$ in color than the reference while the rest of the films were all darker. It can also be noted that all samples with $x$-carrageenan were greener $\left(\Delta \mathrm{a}^{*}\right)$ and bluer $\left(\Delta \mathrm{b}^{*}\right)$ than the reference. The change in color can be attributed to the presence of carrageenan. As the carrageenan increases, the films become darker and greener than the reference. The overall difference $\left(\Delta \mathrm{E}^{*}\right)$ however showed that the closest color to the reference is the $70 / 30$ film. However, with the naked eye, there is no significant difference among the films.
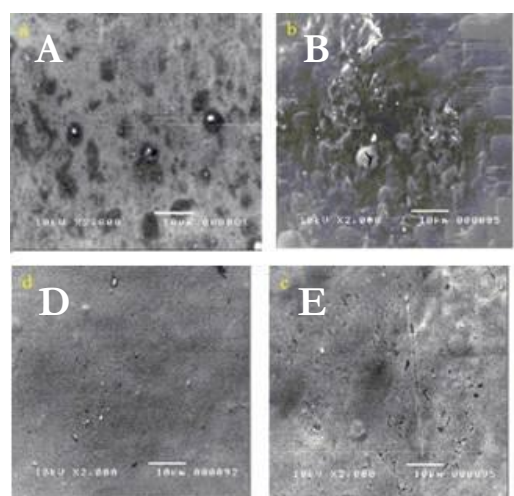

Figure 2: SEM Photograph of the Films with Different Starch/ x-carrageenan (w/w) Ratio Taken at a Magnitude of X2000: (a) 100/0, (b) 90/10, (c) 80/20, (d) 70/30, (e) 60/40, and (f) 50/50.
The surface morphology of the films (Fig. 2) shows varying degrees of smoothness as the ratio changes: from a porous surface (Fig 2a) to the formation of bubble-like images (Fig $2 \mathrm{~b})$. These observations can be attributed to the density differences between $x$-carrageenan and starch. A more homogenous and less porous features can be observed for Fig 2c$2 d$. Film cracks are noticeable on Fig $2 \mathrm{e}-2 \mathrm{f}$ which can be attributed to reduced retrogradation usually observed when starch, particularly amylose, is mixed with kappacarrageenan (Chaplin, 2012).

To further explore the interaction between starch and $x$-carrageenan, the moisture content of the film (Table 2) was measured to determine the effect of the water affinity on the film.

A significant increase $(\mathrm{p}<0.05)$ in moisture content can be observed when $10 \%$ of $x$ carrageenan was added to the starch $(1.22 \%$ increase to $1.37 \%$ ) However, the moisture content decreases as the $\%$ of $x$-carrageenan increases implying that kappa-carrageenan beyond 10\% composition decreases the films' affinity to water. For hydrocolloids, hydrophobic properties are usually observed when intra-molecular bonds increases indicating that $x$-carrageenan affect the network structure of the film.

Table 2: Physico-chemical Properties of Various Blends of Thermoplastic Starch.

\begin{tabular}{ccccccccc}
\hline \% k-car & $\begin{array}{c}\text { \% } \\
\text { Moisture } \\
\text { Content }\end{array}$ & $\begin{array}{c}\text { Water } \\
\text { Solubility }\end{array}$ & aw* & $\mathbf{p H}$ & $\begin{array}{c}\text { WVTR** } \\
\mathbf{g} /\left(\mathbf{m}^{2} / \mathbf{d a y}\right)\end{array}$ & $\begin{array}{c}\text { Thickness } \\
\mathbf{( m m})\end{array}$ & $\begin{array}{c}\text { Tensile } \\
\text { Strength } \\
\mathbf{( M P a})\end{array}$ & $\begin{array}{c}\text { \% } \\
\text { Elongation }\end{array}$ \\
\hline 0 & 1.22 & 36.54 & 0.379 & 4.64 & 82.73 & 0.16 & 1.09 & 2.15 \\
\hline 10 & 1.37 & 65.69 & 0.423 & 6.13 & 11.31 & 0.13 & 8.69 & 32.7 \\
\hline 20 & 1.35 & 68.22 & 0.421 & 6.46 & 2.47 & 0.12 & 10.18 & 39.8 \\
\hline 30 & 1.32 & 75.98 & 0.409 & 6.86 & 6.14 & 0.12 & 15.93 & 20.2 \\
\hline 40 & 0.75 & 87.68 & 0.441 & 6.98 & 108.42 & 0.14 & 19.30 & 17.6 \\
\hline 50 & 0.75 & 94.00 & 0.457 & 7.26 & 17.50 & 0.14 & 25.00 & 11.9 \\
\hline$* a_{w}-$ water activity \\
$* *$ WVTR - Water Vapor Transmission Rate
\end{tabular}

The water solubility of the films was plotted against different proportion of $x$-carrageenan (Figure 3) showing that the solubility of the films increases as the \% carrageenan increases. This can be attributed to the polyelectrolyte nature of the carrageenan, which is more soluble in water than neutral hydrocolloids like starch because the negatively charged sulfate groups are hydrophilic. The higher water solubility of the blend compared to the pure starch is a positive indicator for faster rate of decomposition. 


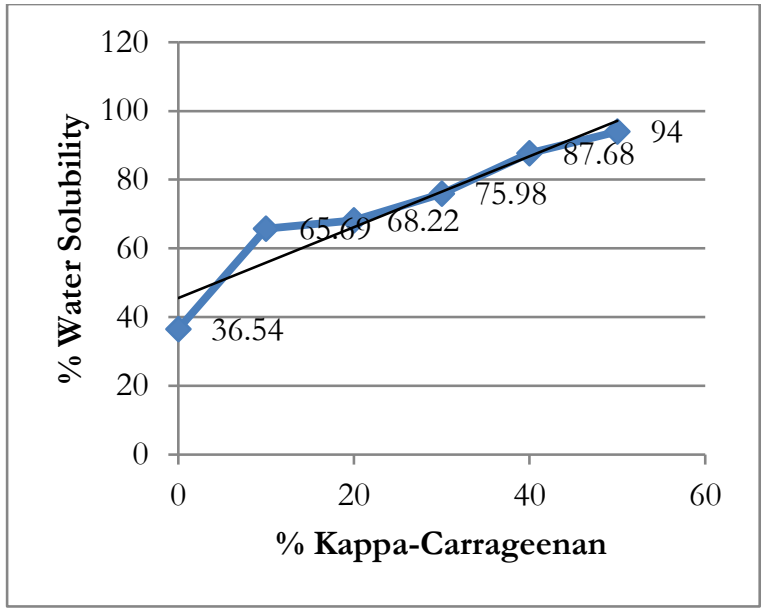

Figure 3: Correlation of Water Solubility with $x$ Carrageenan Content.

The water activity $\left(a_{\mathrm{w}}\right)$ of the film (Table 2 column 4) is a critical factor because it is one of the factors that determines shelf life. It measures water in food which is not bound to food molecules and which can support growth of bacteria, yeasts and fungi. Results show that $a_{w}$ increases as the amount of kappacarrageenan is increased. This observation, however, is contrary to Larotonda's findings (2011) on carrageenan- rice starch blend. The results in the current study indicate that the film is becoming less hydrophilic as the proportion of kappa-carrageenan is increased suggesting that the film can protect the food because pathogen growth is not possible. Note that most bacteria can hardly grow at water activities below 0.91, including pathogens such as Clostridium botulinum (Fontana, 1998). Below 0.80 most molds cannot grow, and below 0.60 no microbiological growth is possible (Fontana, 1998). Thus even at $50 \%$ blend with the highest $a_{w}=0.457$, pathogen growth is less likely to occur. It is important that although $a_{w}$ has increased, it does not reach the limit where it could support bacterial growth.

The expected results on increasing $\mathrm{pH}$ values of the film as the amount of kappacarrageenan is increased is due to the increasing basicity contribution of kappacarrageenan (Balgua, 2005).

The barrier property of the films was measured using water vapor transmission rate (WVTR). The results indicate that, except for
60/40 ratio, the pure thermoplastic starch exhibits lower water barrier property than the composite films. This implies that, generally, incorporation of kappa-carrageenan increases the barrier property of the film. Theoretically, the barrier property is dependent on the thickness of the film. The solution and casting method used in the preparation of these films are less precise compared to spin coating, resulting to inhomogeneity of the film (Martins, et al., 2011). The correlation between film thickness and water vapor permeability (Figure 4) show that at 60/40 starch/kappa-carrageenan ratio, WVTR was observed to become highest. This may be due to lack of thickness uniformity resulting from non-homogeneity in the film-forming solution. The film with 80/20 starch/kappacarrageenan ratio had the highest water vapor barrier $(2.47 \mathrm{~g} / \mathrm{m} 2$ day $)$ comparable to the barrier of vinylidene chloride copolymer (Finnigan, 2009).

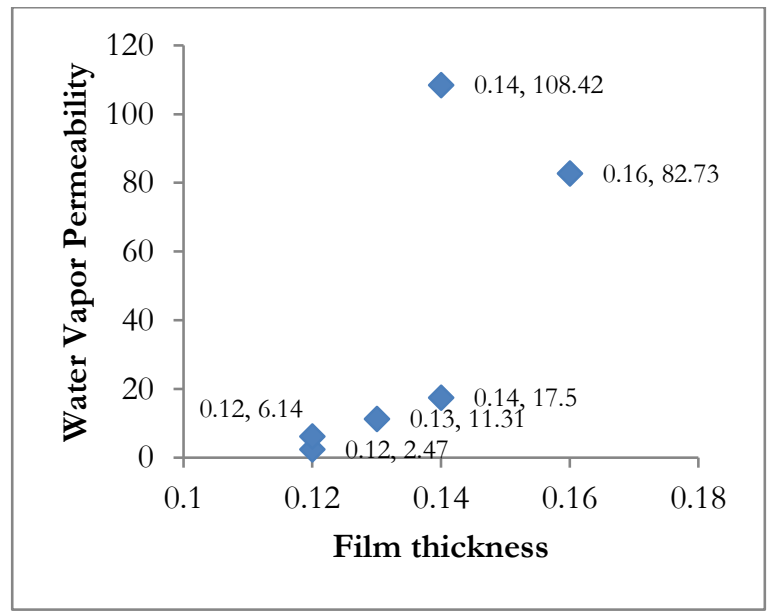

Figure 4: Correlation between Film Thickness and Amount of Kappa-Carrageenan.

The effect of the different ratio of cassava starch and kappa-carrageenan on the mechanical properties of the films is shown in Table 2 columns $8 \& 9$. The highest value of tensile strength is that of the film with $50 / 50$ starch/kappa-carrageenan blend. This can be attributed to the high concentration of kappacarrageenan as it winds around each other to form double helical zones (Chaplin, 2012) causing more rigid network resulting to higher tensile strength. The \% elongation decreased as the amount of kappa-carrageenan is 
increased. This can be attributed to the reduced concentration of starch. Since starch contains two very high molecular weight components, amylose and amylopectin, thermoplastic starch is expected to be a very elastic material. It then follows that as the starch content is reduced (while kappacarrageenan is increased) elongation starts to decrease. This observation was also noted on kappa-carrageenan and its interaction with other polysaccharide (Tecante and Santiago, 2012).

\section{CONCLUSIONS AND RECOMMENDATIONS}

In general, the films produced from cassava starch and kappa-carrageenan have remarkable properties. They presented acceptable appearance in terms of color and transparency. They possess high water solubility and are therefore applicable as a primary packaging, a packaging material that is in direct contact with the commodity e.g. food or pharmaceutical products. The thickness obtained conforms to the standard for commercial sheets and rollings. The water activities are very low thereby pathogens and microbes have slim chance to survive. The mechanical properties were excellent in terms of tensile strength, which can be comparable or even better than the commercial polyethylene which has a tensile strength of about $15 \mathrm{MPa}$. The water vapor permeability exhibited improvement when kappacarrageenan was incorporated into the film. The highest value obtained is $2.47 \mathrm{~g}$ $\mathrm{mil} /\left(\mathrm{m}^{2}\right.$ day $)$ which is comparable to the water vapor permeability of vinylidene chloride copolymers (Finnigan, 2009).

Casting, the method used in this study, is enough to gather information about the film's physical and chemical properties. However, since it is a batch method, it is incorrect to compare the results to the commercial scale. Another drawback of this method, thickness, uniformity, and homogeneity of the film are difficult to control.
Starch and kappa-carrageenan showed to have great potential in the fabrication of edible coating and films. A good possible application would be the sachets of instant noodles seasoning. These sachets are torn open, contents poured to the noodles, and then disposed. Instead of throwing these sachets to the environment, they can be made edible, soluble in hot water, and to be eaten with the noodles.

\section{REFERENCES}

Balgua CT. Synthesis of Compatible Blends of K-Carrageenan with Poly(4-vinylpridine-COvinylacetate) and Poly(4-vinylpiridine-COmethacrylonitrile) [thesis]. Manila, Philippines: De La Salle University, 2005 Aug.

Bourtoom T. Factors Affecting the Properties of Edible Film Prepared from Mung Bean Proteins. Int Food Res J. 2008;15(2):167-180.

Chaplin M. Water Structure and Science [Internet]. [Place unknown]: London South Bank University [cited 2012 May 8]. Available from: http://www.lsbu.ac/water/hydro.html.

Finnigan B. Barrier Polymers. The Wiley Encyclopedia of Packaging Technology. New York: John Wiley \& Sons, Inc.; 2009. p. 103-109.

Fontana A. Water Activity: Why it is Important for Food Safety. Proceedings of the First NSF International Conference on Food Safety; 1998. p. $177-185$.

Larotonda FDS, Hilliou L, Gonçalves MP, Sereno AMC. Physical Properties of Starch Based Edible Films Containing Kappa or Kappa-2 Carrageenan. In: V Congreso Iberoamericano de Ingenieria de Alimentos, 2005, Puerto Vallarta. Proceedings of V CIBIA; 2005.

Martins JT, Cerqueira MA, Bourbon AI, Pinheiro AC, Vicente AA. Edible films-based on $x$-carrageenan/Locust bean gum - effects of different polysaccharide ratios on film properties. 11th International Congress on Engineering and Food; 22-26 May 2011; Athens, Greece. 
McHugh TH, Avena-Bustillos RJ, Wen-Xian D. Extension of Shelf Life and Control of Human Pathogens in Produce by Antimicrobial Edible Films and Coatings. In Fan X, Niemira BA, Doona CJ, Feeherry FE, Gravani RB. Microbial Safety of Fresh Produce. Oxford: Wiley-Blackwell; 2009. p. 225-239.

Muller RJ. Biodegradability of Polymers: Regulations and Methods for Testing. In Biopolymer Online; 2005. p. 365-374.

Perez-Perez C, Regalado-Gonzalez C, Rodriguez-Rodriguez CA, Barbosa-Rodriguez JR, Villasenor-Ortega F. Incorporation of Antimicrobial Agents in Food Packaging Films and Coatings. In Guevara-Gonzales RG, Torres-Pacheco I. Advances in Agricultural and Food Biotechnology. Kerala, India: Research Signpost:, 2006. p. 193-216.
Sothornvit R, Krochta JM. Water Vapor Permeability and Solubility of Films from Hydrolized Whey Protein. J Food Sci. 2000; 65(4):700-703.

Tecante A, Santiago MC. Solution Properties of $x$-Carrageenan and Its Interaction with Other Polysaccharides in Aqueous Media [Internet]. In De Vicente J, ed. Rheology. [Place unknown]: InTech; [cited 16 May 2012]. Available from: http://www.intechopen.com/books/rheology / solution-properties-of-k-carrageenan-and-itsinteraction-with-other-polysaccharides-inaqueous-media. 